[Review]

www.whxb.pku.edu.cn

\title{
纳米多孔金属电催化剂在氧还原反应中的应用
}

\author{
翟 萧 ${ }^{1,3}$ 丁 轶 $2,3,{ }^{*}$ \\ ( ${ }^{1}$ 上海理工大学材料科学与工程学院, 上海 200093 ; ${ }^{2}$ 天津理工大学新能源材料与低碳技术研究院, 材料科 \\ 学与工程学院, 天津 $300384 ;{ }^{3}$ 天津市先进多孔功能材料重点实验室, 天津 300384)
}

\begin{abstract}
摘要: 燃料电池是将化学能直接转化为电能的能量转换装置, 具有绿色、高效、便携等特点。对于大多 数使用氧气或者空气为氧化剂的燃料电池而言, 其阴极氧还原反应动力学缓慢、稳定性差是阻碍该技术 走向商业化的主要因素, 因此开发高催化活性和良好稳定性的低成本氧还原催化剂非常重要。基于脱合 金法制得的纳米多孔金属是一类新型的宏观尺度纳米结构材料, 其独特的开放型孔道结构、优良的导电 性和结构的可调控性使其在电催化相关领域具有广泛的应用。本文侧重于讨论纳米多孔金属作为氧还原 催化剂时所展示的一系列结构特性, 及其在发展新一代高性能一体化燃料电池催化剂中所展示的机会。
\end{abstract}

关键词: 纳米多孔金属; 脱合金; 燃料电池; 氧还原; 低铂催化剂

中图分类号: 0643

\section{Nanoporous Metal Electrocatalysts for Oxygen Reduction Reactions}

\author{
ZHAI Xiao ${ }^{1,3}$ DING Yi, ${ }^{2,3, *}$ \\ ${ }^{1}$ School of Materials Science and Engineering, University of Shanghai for Science and Technology, Shanghai \\ 200093, P. R. China; ${ }^{2}$ Institute for New Energy Materials \& Low-Carbon Technologies, School of Materials \\ Science and Engineering, Tianjin University of Technology, Tianjin 300384, P. R. China; ${ }^{3}$ Tianjin Key Laboratory \\ of Advanced Functional Porous Materials, Tianjin 300384, P. R. China)
}

\begin{abstract}
Fuel cells allow the direct conversion of the chemical energy in chemical fuels to electricity, with particular advantages of being highly effective, environment-friendly, and portable. For those fuel cells using oxygen or air as the oxidant, the oxygen reduction reaction (ORR) occurring on the cathode remains the major obstacle for the commercialization of fuel cell technologies because of its slow kinetics, which in turn results in relatively low catalytic efficiency and high price due to excessive use of precious metals like Pt. In recent years, dealloyed nanoporous metals have garnered widespread attention in the field of electrocatalysis due to their unique structural properties, such as three-dimensionally interconnected pore/ligament structure, excellent conductivity, and structural flexibility. This review summarizes the recent advances in nanoporous metal catalysts for ORR, with an emphasis on their unique structural properties for the development of new-generation high-performance fuel cell catalysts.
\end{abstract}

Key Words: Nanoporous metal; Dealloying; Fuel cell; Oxygen reduction reaction; Low Pt catalyst

1 引 言

能源与生态环境可持续性发展已经成为当今
世界的主题，而目前全球 $80 \%$ 的能耗来源是不可 再生的化石燃料, 化石燃料在使用过程中会释放

Received: February 20, 2017; Revised: April 3, 2017; Published online: April 17, 2017.

*Corresponding author. Email: yding@tjut.edu.cn.

The project was supported by the National Natural Science Foundation of China (51671145).

国家自然科学基金(51671145)资助项目

(C) Editorial office of Acta Physico-Chimica Sinica 
$\mathrm{CO}_{2}$, 从而引起气候变化和其他一系列环境问题。 因此开发可再生清洁能源, 研发高效能源转换、 存败装置是解决此类问题的主要手段。燃料电池 作为本世纪备受关注的新能源技术之一, 可实现 化学能向电能的直接转换, 具有高效、便携、环 境友好等特点, 且使用温度范围较广, 目前已在 可移动电源和城市公共交通等领域成功示范 ${ }^{1-3}$ 。 燃料电池技术目前面临的最大问题是由于技术链 长、造价高昂、目标市场尚不明确等导致一直未 能实现大规模商业应用。从材料角度看, 寻找合 适的材料, 尤其是催化剂材料, 并匹配相应的组 装工艺, 实现制造成本大幅度降低, 同时提高其 功率密度和系统稳定性是燃料电池的最核心技 术。

19 世纪 60 年代, 科学家们即采用将粒径 2-5 $\mathrm{nm}$ 的铂 $(\mathrm{Pt})$ 微晶负载在碳粉或者碳纸上的方式来 降低 $\mathrm{Pt}$ 的载量 ${ }^{2}$, 这也许是最早的纳米结构工程, 也是燃料电池催化剂发展的重要节点。但当前各 类燃料电池仍然使用了过多的 Pt 催化剂, 使得地 球上 Pt 资源特别贵乏的问题额外突出。这个问题 对于中国尤其明显, 因为中国同时是 $\mathrm{Pt}$ 需求大国 和 Pt 资源贵乏国, 每年 Pt 产量不足 4 吨, $90 \%$ 以 上依赖进口 ${ }^{4}$ 。由于阴极氧还原反应机理复杂、反 应动力学缓慢, 阴极催化剂 Pt 载量可比阳极高 8 倍之多 ${ }^{5,6}$, 因此, 近 10 年来, 开发高性能低 $\mathrm{Pt}$ 或非 $\mathrm{Pt}$ 氧还原催化剂已成为燃料电池领域研究的 热点。而脱合金法制备的纳米多孔金属具有可调 控的双连续开放式孔结构、清洁表面、优良的导 电性、制备工艺简单、可自支撑等特点, 这为开 发高效、低 $\mathrm{Pt}$ 或非 $\mathrm{Pt}$ 燃料电池催化剂提供了新的 机会。

\section{2 氧还原反应}

\section{1 氧还原机理}

氧还原反应 $(O R R)$ 是一个多电子反应过程, 其 中间产物较多且难以利用原位检测来进行分析。
研究者们已提出多种 ORR 机理来分析 $\mathrm{O}_{2}$ 在催化 剂表面的还原过程, 目前较为大家接受的解释金 属表面 ORR 复杂过程的是 Wroblowa 机理 ${ }^{7}$ 。以水 溶液中金属表面的 ORR 为例, 该机理认为 $\mathrm{O}_{2}$ 在 金属表面电化学还原时有两种可能路径, 可以通 过 2 电子途径生成中间产物 $\mathrm{H}_{2} \mathrm{O}_{2}$, 也可以通过 4 电子途径直接生成水。其中 $\mathrm{O}_{2}$ 经由 2 电子途径生 成的 $\mathrm{H}_{2} \mathrm{O}_{2}$ 吸附在电极表面, 可以继续进行电化学 还原生成最终产物水, 也可以在电极表面发生催 化分解或者是发生解吸附溶解至溶液中。相较于 2 电子途径, 4 电子途径可有效地提高催化剂催化效 率, 并防止电极支撑材料和质子交换膜等材料被 2 电子途径产生的 $\mathrm{H}_{2} \mathrm{O}_{2}$ 腐蚀。这两种反应途径都包 括了 $\mathrm{O}_{2}$ 分子的解离吸附以及与质子的反应, 其中 含氧物种在催化剂表面的吸附既是实现电子传递 的必需条件, 又是占据催化剂表面活性位点造成 催化效率低下的原因 ${ }^{8-11}$ 。在燃料电池应用中, ORR 催化剂必须在高氧化电位即极易腐蚀的环境 下保持高活性并兼具高稳定性: 既要有足够的化 学活性能够活化 $\mathrm{O}_{2}$ (发生一个电子和一个质子的 转移, 生成吸附 $\left.\mathrm{OOH}^{*}\right)$, 又要有适当的惰性使催 化剂表面的产物 $\mathrm{H}_{2} \mathrm{O}$ 成功解离 ${ }^{12}$ 。因此了解 $\mathrm{O}_{2}$ 在催化剂表面的反应机理是提高 ORR 催化剂效率 和稳定性的关键所在。但在实际的 ORR 反应过程 中, 其中间产物繁多 $\left(\mathrm{O}^{*} 、 \mathrm{OH}^{*} 、 \mathrm{OOH}^{*}\right.$ 等), 且这 些中间产物很难用原位分析方法检测到 ${ }^{13,14}$, 所以 目前对 ORR 机理的认识并不充分。即使是已经得 到广泛研究的贵金属 Pt 基催化剂, 其 ORR 过程 也尚未被完全揭示 ${ }^{7,15-17}$ 。

近年来对 ORR 过程的研究越发深入, 目前公 认可通过调控以下参数来提高 $\mathrm{Pt}$ 催化剂的性能: 1)缩短 Pt 原子间距(几何效应); 2)调控 $d$-带电子状 态使 $d$-带中心下移 (电子结构); 3) 表面粗粮度。其 中通过几何效应和电子结构的调控是通过减弱含 氧物种在 $\mathrm{Pt}$ 催化剂表面的吸附来提高其催化效 率, 而提高表面粗䊁度可有效增加催化剂表面的 活性位点, 从而提高催化效率。

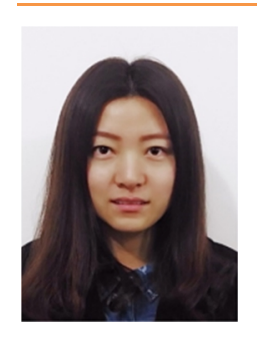

翟萧, 2013 年本科毕业于上海理工 大学材料科学与工程学院, 2015 年 至今为上海理工大学材料科学与工 程学院硕士研究生, 并在天津市先进 多孔功能材料重点实验室联合培养。 主要研究方向为纳米多孔金属电催 化剂的制备及应用。

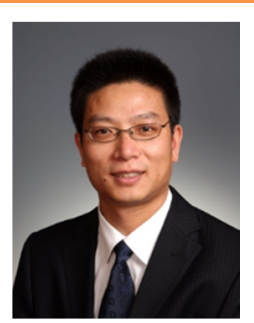

丁轶, 天津理工大学新能源材料 与低碳技术研究院教授。主要从 事纳米多孔金属材料的研发及 在能源、资源、环境等领域中的 应用基础研究。发表学术论文 100 余篇, 被引用 7300 余次, 个人 $\mathrm{H}$ 指数 45 , 授权国内外专 利 30 余项。 


\section{2 氧还原催化剂发展现状}

燃料电池阴极反应主要面临以下问题: 1)电压 损失严重。这一问题主要是由于阴极 ORR 需要较 高过电势, 且阳极燃料分子经质子(或离子)交换膜 渗透到阴极产生混合电位等引起; 2)催化效率低。 如前所述 ORR 实际的中间产物比较复杂, 且这些 中间产物既是电子传递的媒介, 又是造成催化剂 催化效率低下的主要原因。针对以上问题, 研究 者们研发了大量新型 $\mathrm{ORR}$ 催化剂, 例如 $\mathrm{Pt} /$ 贵金 属基、过渡金属化合物、生物材料、大环化合物 和掺杂碳材料催化剂等 ${ }^{18-23}$ 。从综合性能看, $\mathrm{Pt}$ 族贵金属基催化剂目前仍然是最现实的可满足应 用端对电源系统整体要求的材料 ${ }^{19-21,24}$ 。

前文已提到可通过几何效应、电子结构和表 面粗粘度来提高催化剂催化效率, 而研究发现合 金化可以有效改变催化剂的电子结构, 结合材料 的纳米化进而改变催化剂的表面应力和能带结 构, 可达到提高催化剂活性的目的。不同的纳米 结构如纳米花 ${ }^{25}$ 、微纳颗粒 ${ }^{26}$ 、纳米颗粒 ${ }^{27}$ 、纳米 管 ${ }^{28}$ 和核壳纳米结构 ${ }^{29}$ 等都已被报道, 其中核壳 结构的催化剂由于其独特的结构优势可显著提高 ORR 催化剂的催化活性, 同时可降低 Pt 含量, 因 而得到了广泛的关注。图 1 是根据文献资料进一 步归纳的目前常用的制备 Pt-基核壳结构催化剂的 方法 ${ }^{30}$, 由于内层原子与外层原子之间的配位效 应和表面应力的协同作用, 可使催化剂电子结构 $d$-带中心下移 ${ }^{31,32}$, 相较于纯 Pt 催化剂可减弱与 中间产物间的吸附作用, 从而提高其催化活性 ${ }^{29,33}$ 。

如果把纳米晶不同的形貌(团簇、球状颗粒、 线状、管状、片状、枝晶等)考虑在一起, 那么文 献研究的大多数 ORR 催化剂均可视为颗粒型催化

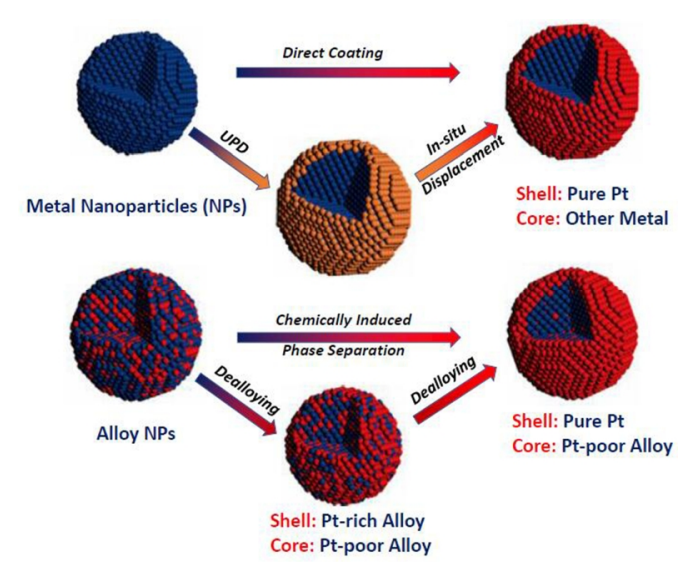

图 1 典型的核壳结构 $\mathrm{Pt}$ 基纳米电催化剂制备方法 ${ }^{30}$

Fig.1 Typical methods for the synthesis of core-shell structured Pt-electrocatalysts ${ }^{30}$.
剂, 而颗粒型催化剂在具体应用时需要与合适的 催化剂载体复合。最常用的催化剂载体是高比表 面碳材料, 这种 “先各自制备一后复合组装” 的催 化剂结构通常会遇到催化剂和载体的兼容性问 题, 这对于需要兼顾结构通透性、导电子性和导 离子性的燃料电池膜电极来说尤其严重。很多 $\mathrm{Pt}$ 颗粒催化剂难以在实际应用中发挥作用。有文献 报道对于碳载铂 $(\mathrm{Pt} / \mathrm{C})$ 纳米催化剂结构, 在然料电 池工况条件下, 仅有不足 $30 \%$ 的 Pt 在发挥作用 ${ }^{34}$ 。 此外, 金属纳米颗粒与碳载体之间作用力通常较 弱, 在工况条件下, 纳米催化剂易脱离载体材料 发生团聚, 这是目前颗粒型催化剂稳定性较差的 主要原因。在这种情况下, 发展具有三维立体结 构的非颗粒型 ORR 催化剂变得十分有价值; 而利 用脱合金法制得的纳米多孔金属由于其三维贯穿 的自支撑韧带孔道结构和优良的机械稳定性, 并 有望同时优化电子、离子和介质分子传递通道, 是一类很有前景的结构型催化剂。

\section{3 纳米多孔金属}

纳米多孔金属是一种由纳米尺度的固体韧带 (孔壁)和孔道在三维空间相互交织构成的海绵状 的金属功能材料 35 。这类结构中的韧带和孔道在 三维空间均可延伸, 这实现了电催化所需的介质 分子和电子的无阻碍传输, 且由于其良好的导电 性、高比表面积和特殊的具有凹/凸曲率的韧带结 构, 使其成为非常有前景的电极材料或构建复合 电极所需的骨架材料, 已在电化学能量存储和转 换的应用中显示出巨大的潜力 ${ }^{36-38}$ 。

\section{1 纳米多孔金属的制备}

纳米多孔金属的制备方法有很多种，如脱合 金法 ${ }^{35}$, 模板法 ${ }^{39}$, 阳极氧化法 ${ }^{40}$, 激光蚀刻法 ${ }^{41}$, 燃烧合成法 ${ }^{42}$, 溶胶-凝胶法 ${ }^{43}$, 热分解法 ${ }^{4}$ 等。 在所有上述方法中, 脱合金法由于原理简单、操 作便捷、参数可调、适用性宽等特点而具有显著 优势, 图 2 是典型的脱合金法制备纳米多孔金属 的工艺流程图。脱合金是一种选择性蚀刻掉合金 材料中的相对活泼元素, 而剩余的相对不活泼元 素自发重组形成纳米多孔骨架结构的电化学过 程。为满足各种应用的需求, 微观结构调控是纳 米多孔金属材料开发的关键。可通过合金前驱体 的设计, 控制脱合金参数, 材料后续热处理和表 面改性等方法进行纳米多孔结构和功能的调控。

\subsection{1 前驱体的选择}

Erlebacher ${ }^{45}$ 提出, 在脱合金过程中产生多孔 结构的合金体系需具有以下基本特征：(i)合金组 


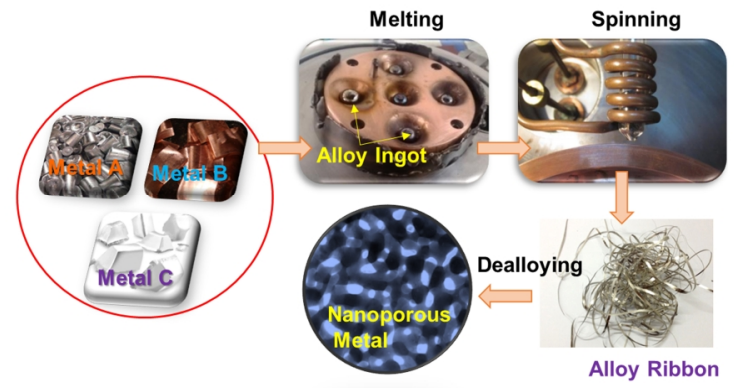

图 2 脱合金法制备纳米多孔金属的典型过程

Fig.2 Schematic illustration of the fabrication process of nanoporous metals by dealloying.

分中不同元素之间的电位差(溶解不同金属单质时 所需电化学电位之间的差值)须达到几百毫伏; (ii) 组分中通常含有比例较大的非贵金属组元(贵金属 组元的含量低于某阈值); (iii)合金必须是均匀的, 在溶解之前不存在相分离, 即多孔结构在溶解过 程中动态形成, 而不是简单两相材料发生了单相 析出和溶解; (iv)贵金属原子在合金/电解质界面处 的扩散必须足够快。基于上述脱合金前驱体选择 标准, 许多合金体系已被探索, 如 $\mathrm{Al}$ 基 ${ }^{46} 、 \mathrm{Zn}$ 基 ${ }^{47} 、 \mathrm{Mg}$ 基 ${ }^{48} 、 \mathrm{Mn}$ 基 ${ }^{49} 、 \mathrm{Cu}$ 基 ${ }^{50} 、 \mathrm{Ni}$ 基 ${ }^{51}$ 合金 等。当然这些特征更多是经验性的, 针对不同的 合金及腐蚀介质均有较宽的可调控范围。

\section{1 .2 脱合金参数控制}

脱合金过程中的一些参数包括电解质溶液的 种类、浓度、腐蚀温度、施加电位、反应持续时 间等都对纳米多孔金属产物的结构形貌有影响。

首先是脱合金方式的选择, 化学或电化学脱合金 都可以获得纳米多孔结构, 但是这两种方法得到 的纳米多孔金属具有不同的特征尺寸, 甚至具有 不同的微观结构 ${ }^{52-54}$ 。脱合金也可以在非水溶液 (有机电解质、金属熔体或超临界流体)中进行, 利 用不同浓度腐蚀液制备的纳米多孔结构其孔径大 小也不同。此外温度也是影响产物结构的重要因 素，低温脱合金可以有效控制纳米多孔金属的孔 径尺寸。一般来说, 温度越低, 贵金属元素的表 面扩散速率就越慢, 因此有助于获得韧带孔道尺 寸较小的纳米多孔金属。而较高的温度会使纳米 多孔金属结构粗化, 但由于应力释放也有助于减 少产物结构中的裂纹, 可改善产物结构均一性和 完整性。在电化学脱合金中电势的选择和施加方 法对纳米多孔结构的形成也有显著影响。通常为 了使非贵金属元素溶解和纳米多孔结构的演变能 够发生, 所施加的电势应当高于其临界电势但低 于贵金属元素的平衡腐蚀电势。
结合不同的脱合金条件是调控纳米多孔结构 的有效方法, 例如 Weissmüller 等 ${ }^{55}$ 报道了通过两 步电化学脱合金法制备具有多级孔结构的纳米多 孔金：第一步脱合金生成作为中间产物的纳米多 孔 AuAg 合金, 将粗化后的合金韧带作为二次腐 蚀的前驱体, 可生成二级孔结构。此外, 越来越 多的研究表明气氛对多孔结构的形成也有一定影 响。如 Strasser 等 ${ }^{56}$ 研究了腐蚀气氛( 空气、 $\mathrm{N}_{2}$ ) 和 颗粒尺寸对 $\mathrm{PtNi}_{3}$ 纳米颗粒化学脱合金结构的影 响。他们发现纳米孔的形成演化与在空气条件下 $\mathrm{Ni}$ 的剧烈溶解有关; 相比之下, 在 $\mathrm{N}_{2}$ 保护下的无 氧酸中脱合金则可抑制多孔结构的演化，从而形 成富 $\mathrm{Pt}$ 表面的固体核壳颗粒结构。为了进一步调 控目标产物的形态结构, 经常对纳米多孔金属进 行退火等后处理, 该过程可以诱导多孔结构粗化 从而得到特定尺寸维度的功能材料 ${ }^{57}$ 。

\section{2 纳米多孔金属的结构特性}

众所周知，纳米材料与纳米结构的制备方法 通常分为 “从上而下(Top-down)” 的材料刻蚀工艺 和 “自下而上(Bottom-up)” 的材料形核生长工艺 两大类。而纳米多孔金属材料的制备过程则有效 结合了这两类工艺的基本特征, 在于其表面上看 是采用了 Top-down 类型的材料溶蚀工艺, 而其微 观组织结构的形成与演化却完全是个 Bottom-up 过程。在脱合金过程中, 越来越多的相对惰性金 属原子被释放出来, 它们会在原有固液界面上以 类似于调幅分解(spinodal decomposition)的机制发 生动态相分离, 其中的固态相在亚纳米尺度形核 生长 ${ }^{58}$ 。因此, 从结构几何看, 纳米多孔金属的 双连续结构和治金学中的合金相变以及嵌段共聚 物相分离产物的形貌极其相似 ${ }^{59,60}$ 。此外, 由于纳 米多孔金属表面原子因配位不饱和而具有较高的 表面扩散速率, 因此可以利用这个特征对其进行 后续的结构调控。如图 3(a-c)所示, 纳米多孔金 属的韧带孔道尺寸可以在低至 2-3 nm, 大到数个 微米的宽范围内进行调控。

\subsection{1 纳米多孔金属的微观结构}

由于纳米多孔金属的微观组织结构通常要比 原始合金前驱体的晶粒尺寸小 2-3 个数量级, 其 显微结构在透射电子显微镜表征时经常体现出多 孔单晶特征(如图 3(d-f))。同时由于脱合金过程大 都可以在无机电解质溶液中进行，无需有机或者 高分子表面修饰试剂的参与, 因此纳米多孔金属 通常具有较为洁净的表面结构。这些结构特征有 助于纳米多孔金属电极的高导电性和高表面反应 活性。此外，这类宏观尺度纳米结构材料也拥有 

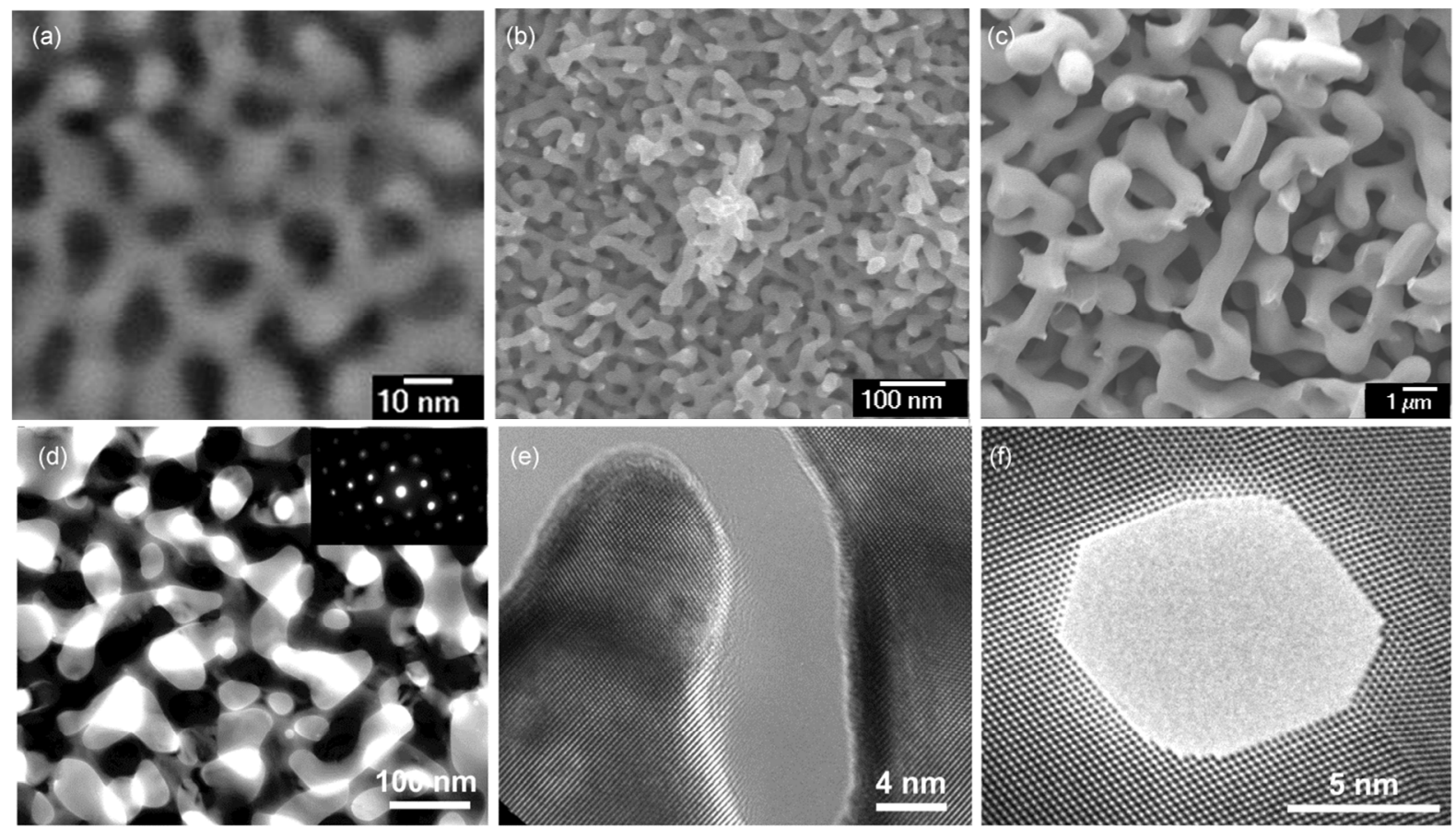

图 $3(\mathrm{a}-\mathrm{c})$ 具有不同特征尺寸的纳米多孔金的 SEM 图像; 纳米多孔金的(d) TEM 图像 ${ }^{61}$; (e-f) HRTEM 图像 ${ }^{62,63}$

Fig.3 (a-c) SEM images of nanoporous gold (NPG) with different pore sizes; (d) TEM ${ }^{61}$ and (e-f) HRTEM image $e^{62,63}$ of NPG.

良好的机械稳定性和导电导热性能 ${ }^{64,65}$ 。电学性能 测试显示, 纳米多孔金电极的导电性能在 $1 \times 10^{-6}$ $\Omega \cdot \mathrm{m}$ 量级, 与传统碳黑或多孔碳电极相比, 其电 阻率至少降低 4 个数量级以上, 这对于后期研发 高功率燃料电池电堆尤其重要。

传统的以模板法、溶胶-凝胶法、热分解法等 手段制得的多孔结构材料, 从微观尺度分析均可 以理解为微纳米颗粒的定向组装, 因此其本征表 面特性基本上与其组装单元微纳米颗粒相似。而 基于脱合金方法制得的纳米多孔金属则没有类似 的组装单元。早在 2007 和 2008 年, Weissmüller ${ }^{68}$ 和 $\mathrm{Chen}^{64,66}$ 课题组独立地实施了透射电子显微镜 断层扫描技术进而实现了纳米多孔金的形貌三维 重构(如图 4a 所示)。定量的数据分析显示, 纳米 多孔金孔道和韧带在拓扑学和形态学上完全等 价。此外, 这样一个随机均匀的双连续结构具有 一定的准周期(quasiperiodic)特性, 韧带和孔道的 界面类似于双曲面, 正负曲率相当, 总表面曲率 接近于零(如图 $4 \mathrm{~b}$ 所示), 从几何上看像一个螺旋 形的 gyroid 结构 ${ }^{69}$ 。最近, Chen 课题组 ${ }^{67}$ 利用球 差矫正扫描透射电子显微镜对纳米多孔金的韧带 结构实施了离散断层扫描分析, 率先实现了纳米 多孔金韧带结构的原子分辨三维重构(如图 4(c-e)
所示)。研究一方面进一步证实了纳米多孔金表面 结构的双曲率几何，也揭示了该多孔结构与传统 的低维纳米颗粒如截角八面体金颗粒(TOP)在表 面低配位原子分布方面具有本质的不同。如图 $4 \mathrm{e}$ 所示, 对于平均韧带/直径尺寸相当的 NPG 和 TOP 而言, 低配位数 $(\mathrm{CN}=5-8)$ 所占表面原子的比例在 NPG 结构中要远远大于 TOP。例如, 韧带尺寸在 $10.3 \mathrm{~nm}$ 的 $\mathrm{NPG}$, 其表面低配位数原子比例仍高达 $42.1 \%$, 显著高于直径在 $3.4 \mathrm{~nm}$ 的金颗粒所能体现 的 $38.1 \%$ 。由于材料表面配位不饱和的原子通常具 有更高的反应活性, 也是各催化反应活性中心的 主要位点, 这一方面能够佐证纳米多孔金属在非 均相催化反应中已经体现出的诸多异常低温反应 特性 ${ }^{70}$, 也预示着它们在电催化方面也将有新的机 会。

\subsection{2 纳米多孔金属的宏观结构}

由于合金前驱体来源丰富, 形貌多样, 而脱 合金过程也有其调控的灵活性, 因此纳米多孔金 属可完美结合金属材料良好的机械性能和纳米材 料优异的界面特性, 这大大拓宽了纳米多孔金属 的应用范围。通过对材料组分和脱合金参数的合 理控制, 具有不同微观组织结构的纳米多孔金属 都可以被制备出来, 从而适应于不同的应用环境。 

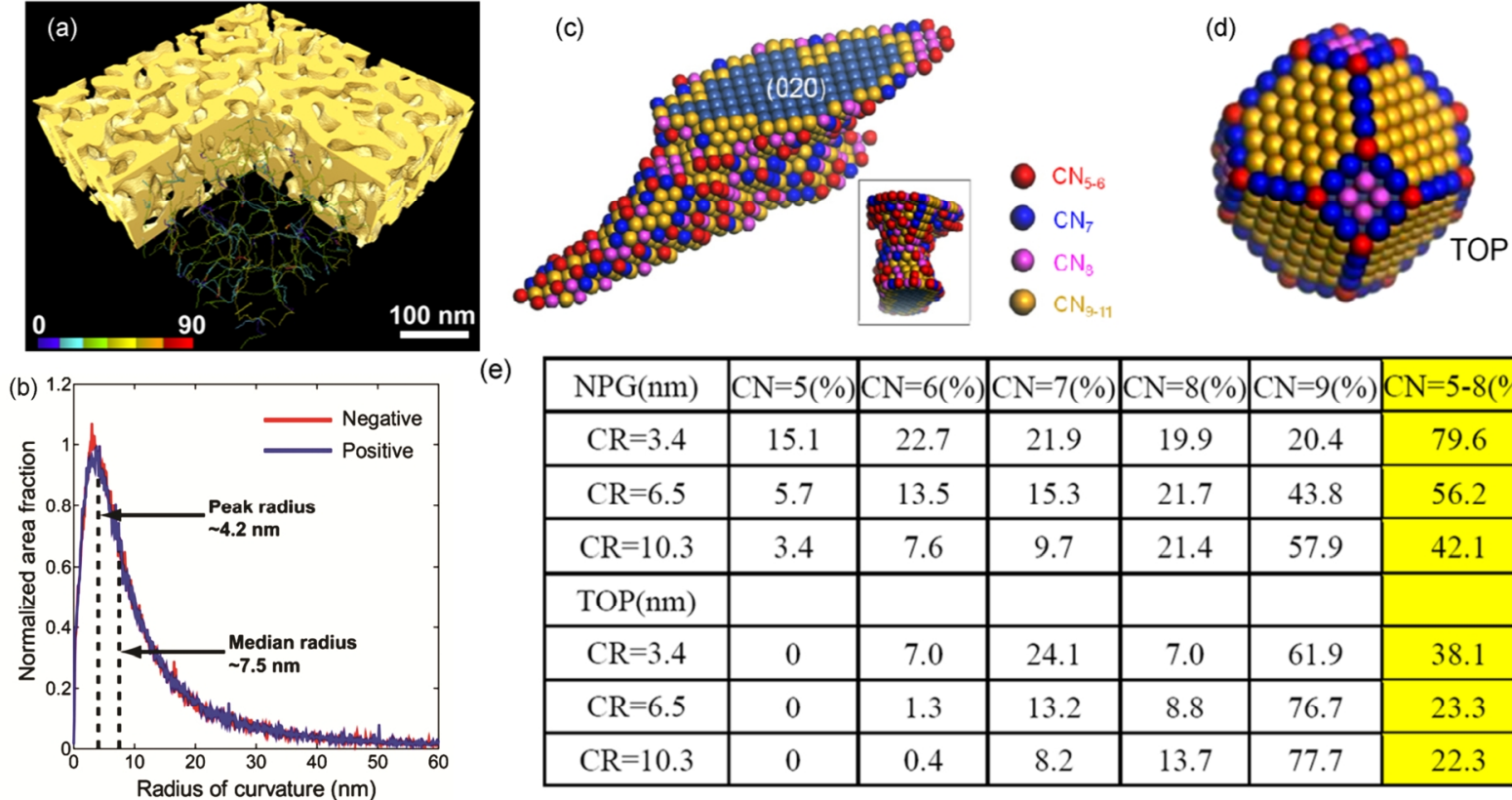

(e)

\begin{tabular}{|c|c|c|c|c|c|c|}
\hline $\mathrm{NPG}(\mathrm{nm})$ & $\mathrm{CN}=5(\%)$ & $\mathrm{CN}=6(\%)$ & $\mathrm{CN}=7(\%)$ & $\mathrm{CN}=8(\%)$ & $\mathrm{CN}=9(\%)$ & $\mathrm{CN}=5-8(\%)$ \\
\hline $\mathrm{CR}=3.4$ & 15.1 & 22.7 & 21.9 & 19.9 & 20.4 & 79.6 \\
\hline $\mathrm{CR}=6.5$ & 5.7 & 13.5 & 15.3 & 21.7 & 43.8 & 56.2 \\
\hline $\mathrm{CR}=10.3$ & 3.4 & 7.6 & 9.7 & 21.4 & 57.9 & 42.1 \\
\hline $\mathrm{TOP}(\mathrm{nm})$ & & & & & & \\
\hline $\mathrm{CR}=3.4$ & 0 & 7.0 & 24.1 & 7.0 & 61.9 & 38.1 \\
\hline $\mathrm{CR}=6.5$ & 0 & 1.3 & 13.2 & 8.8 & 76.7 & 23.3 \\
\hline $\mathrm{CR}=10.3$ & 0 & 0.4 & 8.2 & 13.7 & 77.7 & 22.3 \\
\hline
\end{tabular}

图 4 (a)纳米多孔金的电子断层扫描图像 ${ }^{64}$; (b) 归一化到面积后的韧带曲率半径分布 ${ }^{66}$; (c)纳米多孔金 韧带的原子分辨三维重构图; (d)金纳米颗粒的八面体示意图; (e)不同尺寸的纳米多孔金和截角八面体金颗粒中 表面不同配位数(5-9)的原子所占表面原子的比例 ${ }^{67}$

Fig.4 (a) 3D skeletal network of NPG imaged by electron tomography ${ }^{64}$; (b) Normalized area fractions plotted against radius of curvature of gold ligaments ${ }^{66}$; (c) The reconstructed 3D atomic configuration of an NPG ligament. The color indicates the surface atoms with different coordination number.

(d) Schematic truncated octahedral gold nanoparticle (TOP); (e) fractions of surface atoms with $\mathrm{CN}_{x}(x=5-9)$ out of the total surface atoms of NPG/TOP with different feature sizes ${ }^{67}$.

如图 5 所示, 纳米多孔金属可以是粉末、条带 71 、 薄膜 $^{72,73}$, 也可以是厚度达到几厘米的块体 ${ }^{46}$, 这 种宏观特性不仅为纳米多孔金属的结构多样性提 供了更多的可能，也拓宽了纳米多孔金属的应用 范围。

\section{4 纳米多孔金属氧还原催化剂}

如前所述, ORR 催化剂表面电子结构和配位 效应可影响催化剂与吸附物种间结合能大小, 并
进而决定催化剂综合活性。Norskov 等 ${ }^{74}$ 利用密度 泛函理论揭示了不同金属与其 ORR 催化性能之间 的火山型关系, 其中金属 $\mathrm{Pt}$ 是最好的单金属 $\mathrm{ORR}$ 催化剂, 这与实验结果完全一致。根据这一火山 型关系, 合金化可用于调节(降低)Pt-O 结合能, 而 脱合金制备技术可有效兼顾产物高比表面积和微 观组织结构, 因此, 近年来利用脱合金法制备 ORR 催化剂的文献大量涌现。下面根据已有报道概述 一下纳米多孔 ORR 催化剂近年来取得的主要进
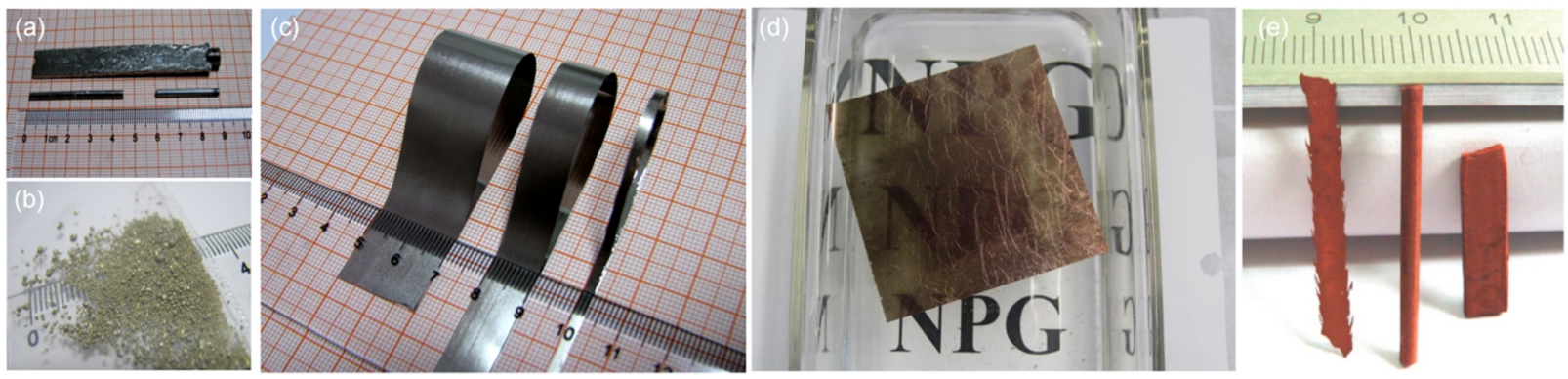

图 $5(a-c)$ 各种类型的合金前驱体; (d-e)相应的宏观尺度纳米多孔金属 ${ }^{46,73}$

Fig.5 (a-c) Various alloy precursors; (d-e) the resulted nanoporous metal membranes and chunks ${ }^{46,73}$. 
展。

\section{1 多孔纳米颗粒}

通过在 Pt 系贵金属表层和次表层掺杂非贵金 属元素 ${ }^{31}$, 或是在非贵金属表面修饰 Pt 是获得高 性能 ORR 催化剂的有效途径 ${ }^{75} 。 2007$ 年, Strasser ${ }^{76}$ 报道了可显著提高商业化碳载铂 $(\mathrm{Pt} / \mathrm{C})$ 催化剂 ORR 性能的简单方法: 将 $\mathrm{Pt} / \mathrm{C}$ 在硝酸铜溶液中浸 渍, 通过高温退火 $\left(600-950{ }^{\circ} \mathrm{C}\right)$ 实现铜盐分解并同 时与 $\mathrm{Pt}$ 合金化生成 $\mathrm{PtCu}$ 双金属纳米粒子。对所得 材料进行电化学脱合金, 发现随着铜的溶出, 产 物的 ORR 逐步提高。结构分析显示, 所获得的电 催化剂内核为 $\mathrm{Pt}_{79} \mathrm{Cu}_{21}$, 表层为 $\mathrm{Pt}_{93} \mathrm{Cu}_{7}$, 其 $\mathrm{ORR}$ 活性比未处理商业 $\mathrm{Pt} / \mathrm{C}$ 提高 4-6 倍。该课题组随 后采用相似的方法对 $\mathrm{Pt} / \mathrm{C}$ 表面修饰铜钴两种金 属, 通过对所获得的三元 $\mathrm{PtCuCo}$ 进行脱合金处 理, 所制得阴极催化剂的 ORR 性能也有显著提高, 并在初步的膜电极测试中得到进一步验证 77 。由 于催化单元尺寸较小, 这些报道未关注脱合金过 程中是否有孔结构形成, 晶格收缩和表面微结构 的变化被认为是 ORR 性能提高的关键。

有关 Pt-基纳米多孔纳米颗粒的制备最早见于 2011 年。 $\mathrm{Li}^{\text {等 }}{ }^{78}$ 发展了化学合成技术制备了单分 散双金属合金纳米颗粒, 然后用脱合金方法去除 其中的活性组分。电子显微分析清楚地证明了多

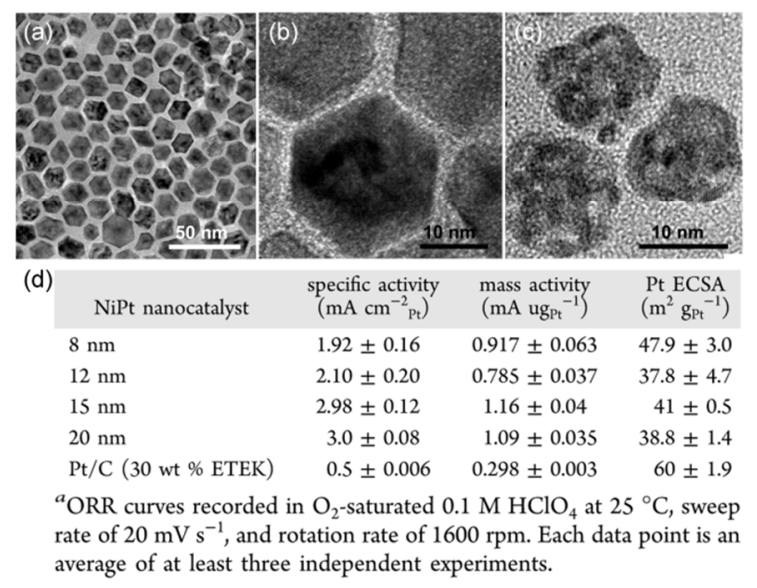

图 $6 \mathrm{Pt}-\mathrm{Ni}$ 纳米颗粒的(a)TEM 图像和(b)HRTEM 图 像; (c)纳米多孔 PtNi 合金的 HRTEM 图像 ${ }^{78}$; (d)脱合金法制备的纳米多孔 PtNi 纳米颗粒和 Pt/C $(30 \%(w))$ 催化剂的性能对比 ${ }^{81}$

Fig.6 (a) TEM and (b) HRTEM images of PtNi alloy nanoparticles, (c) HRTEM image of nanoporous PtNi alloy nanoparticles ${ }^{78}$; (d) iR-Free ORR kinetic activity parameters for dealloyed PtNi catalysts and $30 \%(w) P t / C^{81}$.
孔结构纳米粒子的形成(如图 $6(\mathrm{a}-\mathrm{c})$ 所示)。随后 Oezaslan 等 ${ }^{79}$ 研究了脱合金法制备的二元 Pt-Co 和 $\mathrm{Pt}-\mathrm{Cu}$ 合金纳米颗粒催化剂的形貌结构和粒内 成分与前驱体粒径大小间的关系，他们发现当前 驱体粒径小于 $20 \mathrm{~nm}$ 时, 便无法形成孔结构。而 当前驱体粒径大于 $30 \mathrm{~nm}$ 时，脱合金后的 Pt-基合 金则倾向于形成纳米级的多孔结构。相似的方法 后来被 Erlebacher 等 ${ }^{80,81}$ 采纳去研究纳米多孔 PtNi 纳米颗粒的结构演化及其 ORR 构效关系。通过对 前驱体合金纳米颗粒尺寸和组分的探讨，他们同 样发现只有当合金颗粒粒径大于 $15 \mathrm{~nm}$ 时, 多孔 结构才能形成。所制得的纳米多孔 $\mathrm{PtNi}$ 纳米颗粒 的韧带尺寸小低至 $2 \mathrm{~nm}$, 比表面积比商业 $\mathrm{Pt} / \mathrm{C}$ 略 低, 但总体 Pt 质量 ORR 活性在 $0.9 \mathrm{~V}$ ( v s RHE) 条 件下比 $\mathrm{Pt} / \mathrm{C}$ 高约 4 倍。

利用定位 TEM 电镜技术, Baldizzone 等 ${ }^{82}$ 深 入研究了纳米多孔 $\mathrm{PtNi}$ 纳米颗粒的电化学失活机 理。通过模拟燃料电池真实工况条件实施的加速 老化实验, 发现该多孔阴极催化剂在 0.4-1.0 V (vs RHE), 区间结构和电化学活性比较稳定, 但当电 位区间扩展到 0.4-1.4 V ( vs RHE)时, 多孔结构显 著粗化并导致失活。该工作显示多孔结构 ORR 催 化剂在迈向应用时仍然需要进一步改善其结构稳 定性。

\section{$4.2 \mathrm{Pt}$-基纳米多孔合金}

2010 年, Erlebacher 等 ${ }^{94}$ 报道了用离子液体 改善阴极催化剂 ORR 性能的新思路。他们首先利 用电化学脱合金方法在 $\mathrm{NiSO}_{4}$ 溶液中腐蚀 $\mathrm{Pt}_{23} \mathrm{Ni}_{77}$ 合金条带, 然后在所获得的纳米多孔 $\mathrm{PtNi}$ 合金上 修饰微量的疏水性全氟乙基磺酰基酰亚胺阴离子 基离子液体 $[\mathrm{MTBD}][$ beti]。这类质子型离子液体具 有疏水性、良好的溶氧能力和质子导电性, 因此 可以大幅度改善 PtNi 合金的 ORR 性能。在 $0.9 \mathrm{~V}$ ( vs RHE) 条件下测算的本征动力学电流密度值约 $18.2 \mathrm{~mA} \cdot \mathrm{cm}^{-2}$, 与理想的 $\mathrm{Pt}_{3} \mathrm{Ni}(111)$ 单晶的本征活 性相当, 比商业 $\mathrm{Pt} / \mathrm{C}$ 几乎提高了两个数量级。相 似的方法后来又被该课题组应用于修饰纳米多孔 纳米颗粒阴极催化剂, 同样也获得了很好的性 能 ${ }^{83-85}$ 。

2012 年, Ding 等 ${ }^{86}$ 报道了制备核壳结构纳米 多孔合金阴极催化剂的通用方法。他们首先使用 $\mathrm{NaOH}$ 溶液从组分明确的 PtNiAl 三元合金前驱体 中浸出较活泼的组分 $\mathrm{Al}$, 制备出纳米多孔 $\mathrm{PtNi}$ 合 金; 然后使用 $\mathrm{HNO}_{3}$ 溶液进一步浸出 $\mathrm{PtNi}$ 㓞带表 层的组分 $\mathrm{Ni}$, 最后可获得表层纯铂内核为 $\mathrm{PtNi}$ 合 金的核壳结构纳米多孔 PtNi 表面合金阴极催化 
(a)
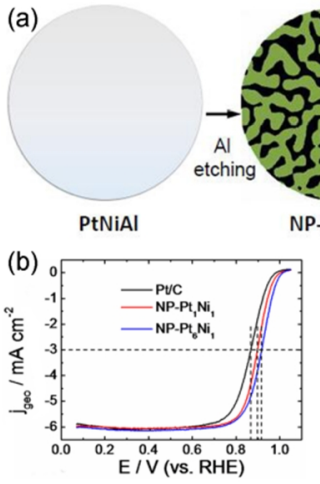
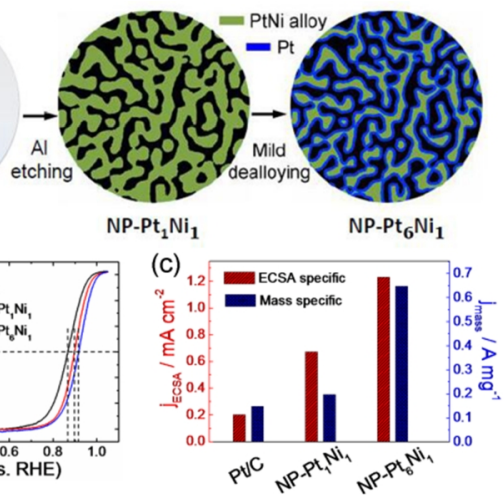

图 7 (a)脱合金法制备纳米多孔 PtNi 合金催化剂 示意图; (b)纳米多孔 PtNi 合金催化剂和 $\mathrm{Pt} / \mathrm{C}$ 催化剂的极化曲线图; (c) $0.9 \mathrm{~V}$ (vs RHE)处质量 活性和面积活性对比图 ${ }^{86}$

Fig.7 (a) Schematic illustration of the fabrication process of nanoporous PtNi surface alloy catalyst; (b) ORR polarization curves and (c) ECSA and Pt mass specific kinetic current densities at $0.9 \mathrm{~V}$ (vs RHE) for nanoporous $\mathrm{PtNi}$ and $\mathrm{Pt} / \mathrm{C}^{86}$.

剂。他们比较了所获得的表观组分为 $\mathrm{Pt}_{1} \mathrm{Ni}_{1}$ 和 $\mathrm{Pt}_{6} \mathrm{Ni}_{1}$ 的两种电催化剂的 $\mathrm{ORR}$ 性能, 如图 7 所示, 在相同实验条件下其半波电位分别为 0.897 和

$0.916 \mathrm{~V}$, 分别比商业 $\mathrm{Pt} / \mathrm{C}$ 催化剂 $(0.866 \mathrm{~V})$ 高出 31 和 $50 \mathrm{mV}$ 。尤其是核壳结构纳米多孔 $\mathrm{Pt}_{6} \mathrm{Ni}_{1}$ 合金, 其 $0.9 \mathrm{~V}$ ( v $\mathrm{RH}^{\mathrm{R} H}$ )处 $\mathrm{Pt}$ 质量活性可达到 0.65 $\mathrm{A} \cdot \mathrm{mg}^{-1}$, 比 $\mathrm{Pt} / \mathrm{C}$ 提高 5 倍以上。此外这类催化剂 还表现出比 $\mathrm{Pt} / \mathrm{C}$ 更好的电化学稳定性。Pt 和 $\mathrm{Ni}$ 之间的合金化效应和材料表面应变(压缩)效应被 认为是这类材料具有较高 ORR 本征活性的原因; 而其开放的纳米孔道结构也便于物质传输, 有助 于电极反应动力学过程。

相似的方法后来被 $\mathrm{Xu}^{87-90}$ 和 $\mathrm{Zhang}{ }^{91-93}$ 等课 题组发展应用于制备其他纳米多孔 PtM $(\mathrm{M}=\mathrm{Pd}$, $\mathrm{Cu}, \mathrm{Fe}, \mathrm{Ti}, . .$. ) 合金阴极催化剂。其反应前驱体通常 是 PtMX 三元乃至更多元合金, 其中 $X$ 是比 $\mathrm{Pt}$ 和 $\mathrm{M}$ 更活泼的金属元素，例如 $\mathrm{Al} 、 \mathrm{Mg}$ 等。通过调 控 $\mathrm{Pt} / \mathrm{M}$ 之间的比例以及 $\mathrm{X}$ 的溶出过程, 可以有效 调控纳米多孔合金产物的比表面积、表面组分和 结构, 进而达到增强其 ORR 催化活性和稳定性的 目的。

2014 年, Jiang 课题组 ${ }^{94}$ 以 $\mathrm{Pt}_{12} \mathrm{Al}_{88}$ (原子百分 比)合金条带为前驱体, $1 \mathrm{~mol} \cdot \mathrm{L}^{-1} \mathrm{NaOH}$ 溶液为电 解质，氮气保护下脱合金制得了具有双级孔分布 的纳米多孔 PtAl 合金 ORR 催化剂。如图 8 所示, 整体材料呈现典型的双连续纳米多孔结构, 此外, 在 $30 \mathrm{~nm}$ 直径的韧带上广泛分布有约 $4 \mathrm{~nm}$ 的孔
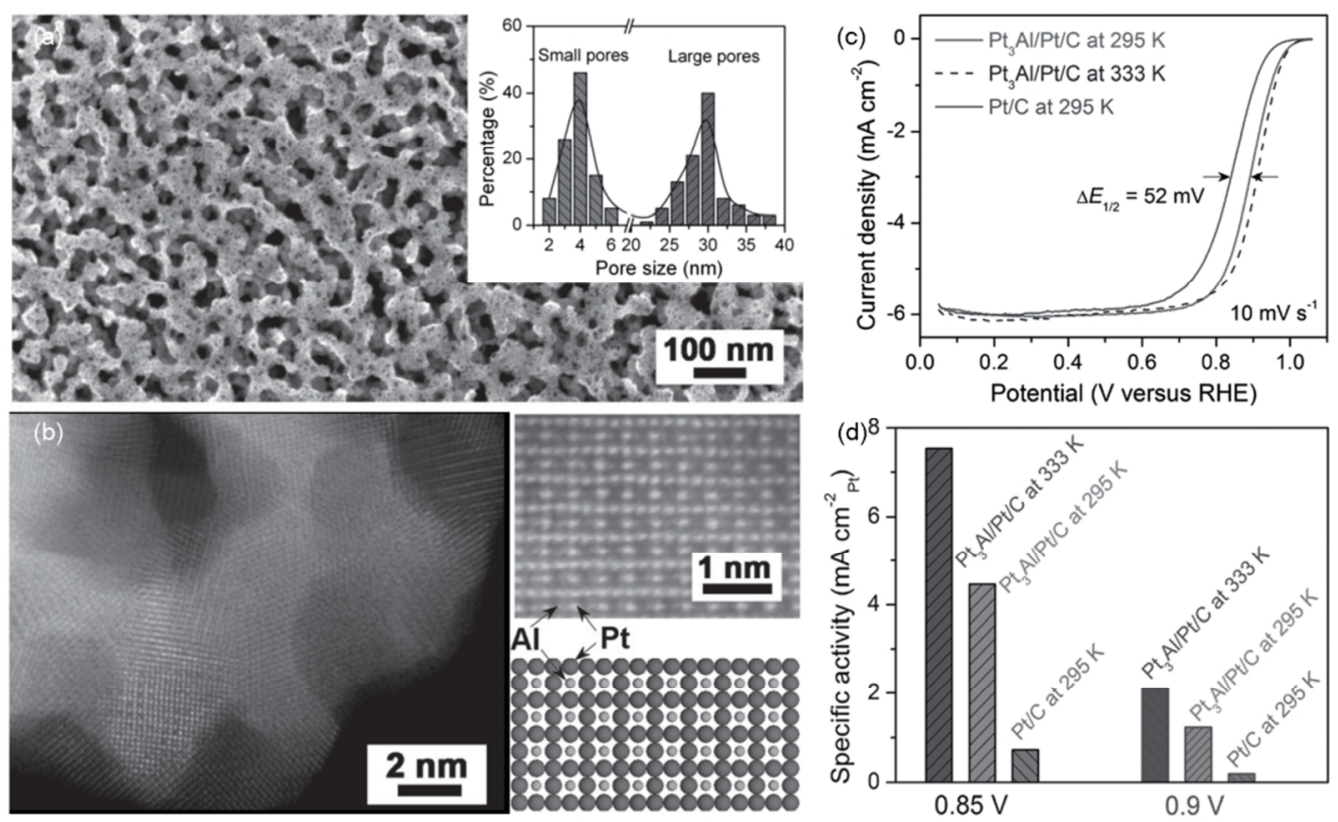

图 8 (a)纳米多孔 $\mathrm{Pt}_{3} \mathrm{Al} / \mathrm{Pt}$ 的 SEM 图像和孔径分布图(内嵌图); (b) 纳米多孔 $\mathrm{Pt}_{3} \mathrm{Al} / \mathrm{Pt}$ 的 HAADF-STEM 图、

超晶格放大图和相应原子结构模型; (c,d)纳米多孔 $\mathrm{Pt}_{3} \mathrm{Al} / \mathrm{Pt} / \mathrm{C}$ 和 $\mathrm{Pt} / \mathrm{C}$ 的 $\mathrm{ORR}$ 极化曲线和比面积活性对比图

Fig.8 (a) SEM image of $\mathrm{Pt}_{3} \mathrm{Al} / \mathrm{Pt}$ and pore size distribution (inset); (b) HAADF-STEM images of $\mathrm{Pt}_{3} \mathrm{Al}$ with super lattice feature and simulated atomic model; (c) ORR polarization curves of $\mathrm{Pt}_{3} \mathrm{Al} / \mathrm{Pt} / \mathrm{C}$ and $\mathrm{Pt} / \mathrm{C}$; (d) Comparison of specific kinetic activity for $\mathrm{Pt}_{3} \mathrm{Al} / \mathrm{Pt} / \mathrm{C}$ and $\mathrm{Pt} / \mathrm{C}$. 
洞。精细的球差电镜分析显示, 材料体相是 $\mathrm{Pt}_{3} \mathrm{Al}$ 或 $\mathrm{Pt}_{5} \mathrm{Al}$ 结构的金属间化合物, 表层覆盖有原子级 别厚度的纯铂。基于实验结果, 他们实施了密度 泛函理论(DFT)模拟, 证实受内部压缩应力和表面 配位效应的影响, 表层 Pt 电子结构 $d$ 带中心发生 下移, 可有效削弱 Pt 与氧化物种之间的结合, 从 而改善其 ORR 活性。电化学测试也确实证明, 所 制得材料电化学比活性在 $0.9 \mathrm{~V}$ (vs RHE) 比商业 $\mathrm{Pt} / \mathrm{C}$ 提高 5-6.3 倍。尤其重要的是, 该材料还具有 优异的电化学稳定性和高温活性。在氮气保护的 $0.1 \mathrm{~mol} \cdot \mathrm{L}^{-1} \mathrm{HClO}_{4}$ 溶液中, 以 $50 \mathrm{mV} \cdot \mathrm{s}^{-1}$ 的速率在 0.6-1.1 V ( vs RHE) 电位区间循环 40000 圈之后, 商业 $\mathrm{Pt} / \mathrm{C}$ 催化剂半波电位发生了 $75 \mathrm{mV}$ 的负移, 而纳米多孔 PtAl 合金催化剂只发生了约 $20 \mathrm{mV}$ 的 负移。

\section{3 非 Pt 纳米多孔金属}

由于 $\mathrm{Pt}$ 资源稀缺且价格昂贵, 近年来也有大 量的研究致力于开发新型非 Pt 催化剂。以掺杂碳 材料为代表的非 Pt 催化剂是该方向的研究热点, 但其总体催化活性与 $\mathrm{Pt}$ 族金属相比仍有显著差 距, 尤其是在酸性体系中 ${ }^{14}$ 。Erlebacher 等 ${ }^{95}$ 曾研 究脱合金腐蚀 $\mathrm{AuAg}$ 合金得到的纳米多孔金的 ORR 活性, 发现纳米多孔金可通过两个 2 电子反 应逐步将 $\mathrm{O}_{2}$ 还原为 $\mathrm{H}_{2} \mathrm{O}$ 。尤其是其第二步从 $\mathrm{H}_{2} \mathrm{O}_{2}$ 还原到 $\mathrm{H}_{2} \mathrm{O}$ 的过程非常迅速, 并且随着材料㓞带 尺寸的减小, 其 $\mathrm{H}_{2} \mathrm{O}_{2}$ 催化还原活性提高。他们认 为多孔结构有效增加了 $\mathrm{Au}$ 表面的低配位数反应 活性位点, 使得反应顺利进行。当然, 总体而言 纳米多孔金的 ORR 催化活性与 Pt 相比仍然相差 甚远。在各类金属元素中, 只有 Pd 的 ORR 活性 比较接近 $\mathrm{Pt}^{96}$, 且相对更便宜。但 $\mathrm{Pd}$ 的化学稳定
性较差, 需要通过与其它组分形成复合结构以改 善其综合电化学性能。

2009 年, Ding 等报道了利用 $\mathrm{CuAl}$ 脱合金制 得的纳米多孔铜 (NPC) 作为模板和还原剂如 $\mathrm{H}_{2} \mathrm{PtCl}_{6}, \mathrm{~K}_{2} \mathrm{PdCl}_{4}$ 通过简单的置换反应, 制备出具 有三连续多级结构的 $\mathrm{PtCu}$ 和 $\mathrm{PdCu}$ 双金属电催化 剂 97,98 。在置换反应中, 贵金属元素不断沉积在纳 米多孔铜㓞带表面, 而内层 $\mathrm{Cu}$ 原子不断被消耗, 最终形成中空管状结构。所制得电催化剂总体呈 现三维纳米多孔结构, 而其韧带则是合金纳米管, 管直径约 $60 \mathrm{~nm}$, 而壳层厚度在 4-10 nm 之间, 并 由更细小的合金纳米颗粒组成。在 $0.1 \mathrm{~mol} \cdot \mathrm{L}^{-1}$ $\mathrm{HClO}_{4}$ 溶液中, 其 $\mathrm{ORR}$ 极化曲线半波电位为 0.84 $\mathrm{V}$, 显著优于商业 $\mathrm{Pd} / \mathrm{C}$ 催化剂的 $0.78 \mathrm{~V}$, 与商业 $\mathrm{Pt} / \mathrm{C}$ 相当 ${ }^{97}$ 。利用第 4.2 节中提及的脱合金方法对 含 Pd 多元合金进行腐蚀处理, 也可以简便地获得 结构组分可控的纳米多孔 $\mathrm{Pd}$ 基合金, 如 $\mathrm{PdCu}^{97,99,100}, \mathrm{PdFe}^{90}, \mathrm{PdCo}^{101-103}, \mathrm{PdNi}^{102}$, 和 $\mathrm{PdTi}^{103}$ 等。尤其是基于 PdTiAl 脱合金制得的纳米 多孔 PdTi 合金, 实验测得其 ORR 活性和稳定性 均比 $\mathrm{Pt} / \mathrm{C}$ 好, 尤其是其对甲醇氧化几乎没有活性, 因此是非常有希望的直接醇燃料电池阴极催化 剂。

近年来碱性燃料电池研究的复苏也吸引了相 应高性能 ORR 催化剂的研发。由于碱性条件下许 多电极材料都拥有良好的电催化活性, 因此开发 以 $\mathrm{Pt} 、 \mathrm{Pd} 、 \mathrm{Au} 、 \mathrm{Ru}$ 等贵金属材料为主的阴极催化 剂价值相对有限。相比之下, 虽同属贵金属, 银 的经济适用性要强很多。Jiao 等 ${ }^{104}$ 研究了经 $\mathrm{AgAl}$ 脱合金制得的纳米多孔 $\mathrm{Ag}^{105}$ 在碱性条件下的 ORR 性能, 发现其与 $\mathrm{Pt} / \mathrm{C}$ 和体相 $\mathrm{Ag}$ 相比具有更
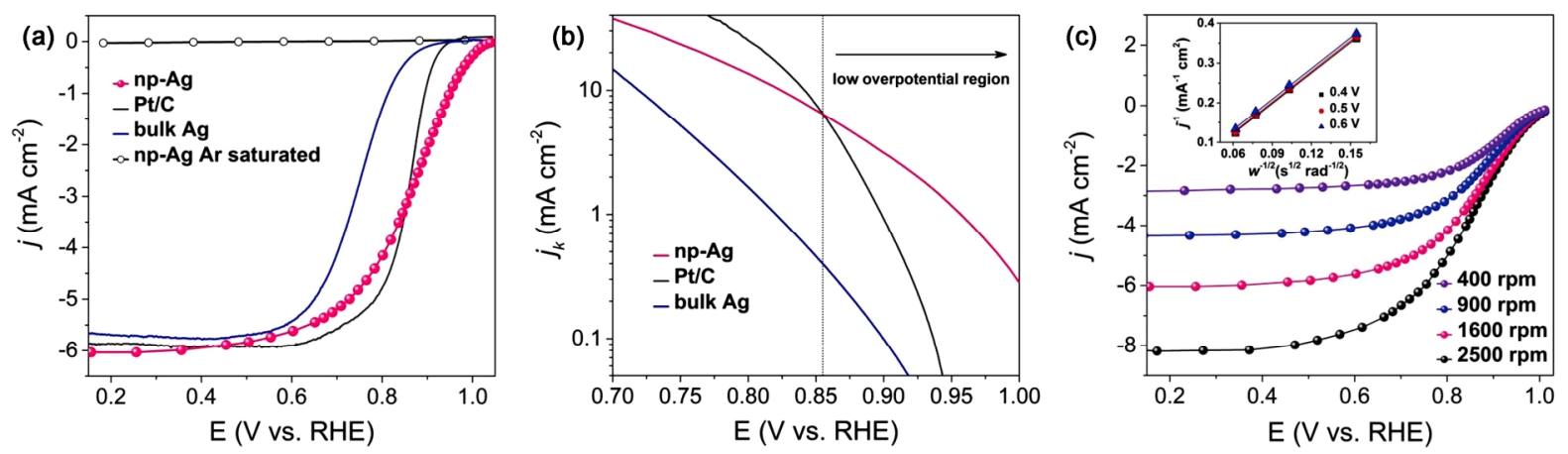

图 9 纳米多孔银(np-Ag), Pt/C 和块体 $\mathrm{Ag}$ 的(a) ORR 极化曲线和(b) Tafel 曲线; (c) np-Ag 循环 5000 圈前后的

ORR 极化曲线和相应的 Tafel 曲线(内嵌图) ${ }^{104}$

Fig.9 (a) ORR polarization curves and (b) Tafel plots of np-Ag, Pt/C, and bulk Ag; (c) ORR curves and corresponding Tafel plots of np-Ag before and after 5000 potential (inset) ${ }^{104}$. 

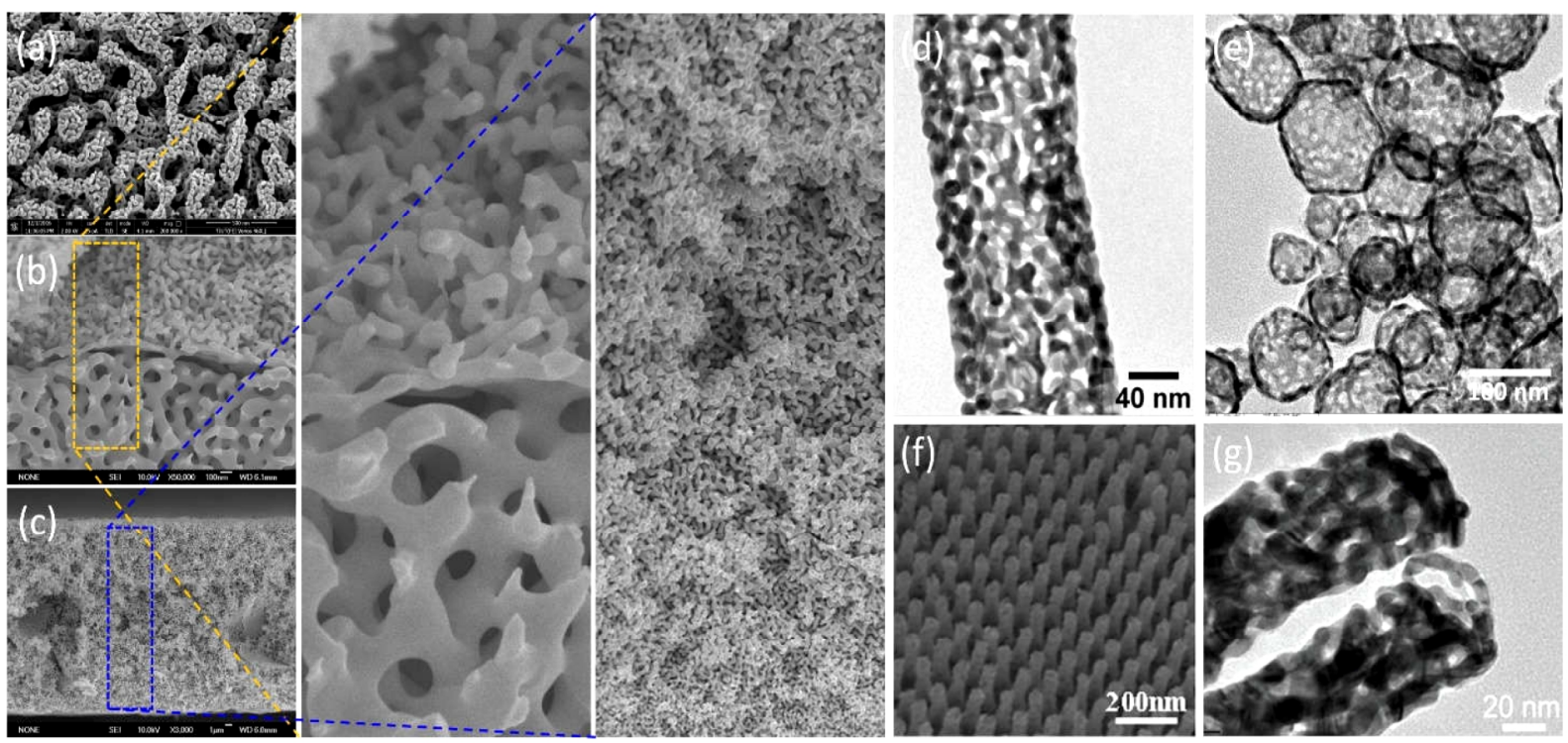

图 10 基于脱合金方法可实现复杂结构多孔电极的设计与合成。(a)多级孔; (b)层次孔；(c)梯度孔；

(d)多孔纳米管 ${ }^{71,106}$; (e)多孔纳米胶囊; (f, g)多孔纳米棒及阵列结构 ${ }^{107}$

Fig.10 Dealloying allows customized design and fabrication of various hierarchically porous electrode materials, such as (a) multimodal porosity; (b) layer structure; (c) gradient porosity; (d) porous nanotubes ${ }^{71,106}$;

(e) porous nanocapsules; (f,g) porous nanowires and arrays ${ }^{107}$.

低过电势, 并通过计算电子转移数确认为 4 电子 ORR 反应。他们推测纳米多孔 $\mathrm{Ag}$ 结构内部和外 部的 $\mathrm{Ag}$ 原子可能具有不同的电化学行为, 但未解 释原因。其中一个可能的解释是孔道内部 $\mathrm{Ag}$ 原子 与表面 $\mathrm{Ag}$ 原子具有不同配位数和空间环境, 因而 具有不同的反应活性。如图 9 所示, 纳米多孔 $\mathrm{Ag}$ 阴极催化剂在低过电势区具有更大的电流密度, 且在循环 5000 圈后几乎没有电流损失。这表明纳 米多孔 $\mathrm{Ag}$ 在碱液中具有良好的 ORR 催化活性和 稳定性。

\section{5 结论与展望}

纳米多孔金属材料经过十多年的发展已经取 得了长足的进步, 其合金原材料来源丰富, 制备 过程简单灵活, 产物结构可控且易于宏量制备。 通过与其它材料制备工艺相结合，纳米多孔金属 电极材料可以实现功能导向的设计。例如, 图 10 展示了基于脱合金制备技术可获得的各类复杂的 多孔电极结构, 包括了多级孔、层次孔、梯度孔、 多孔纳米管、多孔纳米胶囊、多孔纳米棒及阵列 结构。各功能单元的尺寸及组分可以相对独立调 控, 因此理论上有望调和现有燃料电池膜电极结 构中的三相界面困境, 即催化活性和稳定性的匹 配、电子导电性和离子导电性的匹配、高通透性
和高体积密度的匹配、和各电池部件之间亲疏水 的匹配等。

也应该看到，纳米多孔金属材料的研发整体 上还处于积累数据和探索可行性的 “试错” 阶段。 以燃料电池催化为例, 大部分的研究尚未针对膜 电极现有问题来开展。许多材料一方面与现有膜 电极工艺不兼容, 另外受限于其结构, 难以在实 际电池中进行性能评估。如何理性设计并精准合 成有明确功能的电极材料, 首先要理解膜电极乃 至系统层面上电子、质子传递和物料输运之间的 协调, 以及各反应界面稳定性, 而这有待于材料 学、电化学和电池工程各相关领域的同行通力协 作。这既是学术领域的发展趋势，也是相关产业 革新的必由之路。

\section{References}

(1) Brandon, N. P.; Skinner, S.; Steele, B. C. H. Annu. Rev. Mater Res. 2003, 33 (1), 183. doi: 10.1146/annurev.matsci.33.022802.094122

(2) Steele, B. C. H.; Heinzel, A. Nature 2001, 414 (6861), 345. doi: $10.1038 / 35104620$

(3) Carrette, L.; Friedrich, K. A.; Stimming, U. ChemPhysChem 2000, 1 (4), 162. doi:

10.1002/1439-7641(20001215)1:4<162::AID-CPHC162>3.0.CO;2-Z

(4) http://www.chinabaike.com/z/keji/ck/528495.html (accessed Dec 28, 
2016).

(5) Wagner, F. T.; Lakshmanan, B.; Mathias, M. F. J. Phys. Chem. Lett. 2010, 1 (14), 2204. doi: 10.1021/jz100553m

(6) Bondarenko, A. S.; Stephens, I. E. L.; Hansen, H. A.; Perez-Alonso, F. J.; Tripkovic, V.; Johansson, T. P.; Rossmeis1, J.; Norskov, J. K.; Chorkendorff, I. Langmuir 2011, 27 (5), 2058. doi: 10.1021/la1042475

(7) Markovic, N. M.; Schmidt, T. J.; Stamenkovic, V.; Ross, P. N. Fuel Cells 2001, 1 (2), 105. doi: 10.1002/1615-6854(200107)1:23.0.CO;2-9

(8) Xia, Z. H.; An, L.; Chen, P. K.; Xia, D. G. Adv. Eng. Mater. 2016, 6 (17), 1600458. doi: 10.1002/aenm.201600458

(9) Xia, W.; Mahmood, A.; Liang, Z. B.; Zou, R. Q.; Guo, S. J. Angew. Chem. Int. Ed. 2016, 55 (8), 2650. doi: 10.1002/anie.201504830

(10) Raj, C. R.; Samanta, A.; Noh, S. H.; Mondal, S.; Okajima, T.; Ohsaka, T. J. Mater. Chem. A 2016, 4 (29), 11156. doi: 10.1039/c6ta03300h

(11) Liu, Y. Y.; Yue, X. P.; Li, K. X.; Qiao, J. L.; Wilkinson, D. P.; Zhang, J. J. Coord. Chem. Rev. 2016, 315, 153. doi: 10.1016/j.ccr.2016.02.002

(12) Greeley, J.; Stephens, I. E. L.; Bondarenko, A. S.; Johansson, T. P.; Hansen, H. A.; Jaramillo, T. F.; Rossmeisl, J.; Chorkendorff, I.; Norskov, J. K. Nat. Chem. 2009, 1 (7), 552. doi: 10.1038/nchem.367

(13) Gewirth, A. A.; Thorum, M. S. Inorg. Chem. 2010, 49 (8), 3557. doi: $10.1021 /$ ic 9022486

(14) Gasteiger, H. A.; Kocha, S. S.; Sompalli, B.; Wagner, F. T. Appl. Catal., B 2005, 56 (1-2), 9. doi: 10.1016/j.apcatb.2004.06.021

(15) Stephens, I. E. L.; Bondarenko, A. S.; Gronbjerg, U.; Rossmeisl, J.; Chorkendorff, I. Energy Environ. Sci. 2012, 5 (5), 6744. doi: $10.1039 / \mathrm{c} 2 \mathrm{ee} 03590 \mathrm{a}$

(16) Zhu, C. Z.; Li, H.; Fu, S. F.; Du, D.; Lin, Y. H. Chem. Soc. Rev. 2016, 45 (3), 517. doi: $10.1039 / \mathrm{c} 5 \mathrm{cs} 00670 \mathrm{~h}$

(17) Zhou, M.; Wang, H. L.; Guo, S. J. Chem. Soc. Rev. 2016, 45 (5), 1273. doi: $10.1039 / \mathrm{c} 5 \operatorname{cs} 00414 \mathrm{~d}$

(18) Gao, M. R.; Jiang, J.; Yu, S. H. Small 2012, 8 (1), 13. doi: 10.1002/smll.201101573

(19) Shahgaldi, S.; Hamelin, J. Carbon 2015, 94, 705. doi: 10.1016/j.carbon.2015.07.055

(20) Sakaushi, K.; Antonietti, M. Acc. Chem. Res. 2015, 48 (6), 1591. doi: 10.1021/acs.accounts.5b00010

(21) Nie, Y.; Li, L.; Wei, Z. D. Chem. Soc. Rev. 2015, 44 (8), 2168. doi: $10.1039 / \mathrm{c} 4 \operatorname{cs} 00484 \mathrm{a}$

(22) Bashyam, R.; Zelenay, P. Nature 2006, 443 (7107), 63. doi: 10.1038 /nature 05118

(23) Peng, S.; Guo, H. L.; Kang, X. F. Acta Phys. -Chim. Sin. 2014, 30, 1778. [彭三, 郭慧林, 六晓峰. 物理化学学报, 2014, 30, 1778.] doi: 10.3866/PKU.WHXB201407112

(24) Stoerzinger, K. A.; Risch, M.; Han, B. H.; Shao-Horn, Y. ACS Catal. 2015, 5 (10), 6021. doi: 10.1021/acscatal.5b01444

(25) Sun, S. H.; Yang, D. Q.; Villers, D.; Zhang, G. X.; Sacher, E.; Dodelet,
J. P. Adv. Mater. 2008, 20 (3), 571. doi: 10.1002/adma.200701408

(26) Cheng, F. Y.; Su, Y.; Liang, J.; Tao, Z. L.; Chen, J. Chem. Mater. 2010, 22 (3), 898. doi: 10.1021/cm901698s

(27) Sun, J. Z.; Shi, J.; Xu, J. L.; Chen, X. T.; Zhang, Z. H.; Peng, Z. Q. J. Power Sources 2015, 279 (17), 334. doi: 10.1016/j.jpowsour.2015.01.025

(28) Chen, Z.; Waje, M.; Li, W.; Yan, Y. Angew. Chem. Int. Ed. 2007, 46 (22), 4060. doi: 10.1002/anie.200700894

(29) Chen, C.; Kang, Y. J.; Huo, Z. Y.; Zhu, Z. W.; Huang, W. Y.; Xin, H. L. L.; Snyder, J. D.; Li, D. G.; Herron, J. A.; Mavrikakis, M.; Chi, M. F.; More, K. L.; Li, Y. D.; Markovic, N. M.; Somorjai, G. A.; Yang, P. D.; Stamenkovic, V. R. Science 2014, 343 (6177), 1339. doi: 10.1126/science. 1249061

(30) Yang, H. Angew. Chem. Int. Ed. 2011, 50 (12), 2674. doi: 10.1002/anie. 201005868

(31) Stamenkovic, V.; Mun, B. S.; Mayrhofer, K. J. J.; Ross, P. N.; Markovic, N. M.; Rossmeisl, J.; Greeley, J.; Norskov, J. K. Angew. Chem. Int. Ed. 2006, 45 (18), 2897. doi: 10.1002/anie.200504386

(32) Paulus, U. A.; Wokaun, A.; Scherer, G. G.; Schmidt, T. J.; Stamenkovic, V.; Markovic, N. M.; Ross, P. N. Electrochim. Acta 2002, 47 (22-23), 3787. doi: 10.1016/s0013-4686(02)00349-3

(33) Yang, R. Z.; Leisch, J.; Strasser, P.; Toney, M. F. Chem. Mater. 2010, 22 (16), 4712. doi: 10.1021/cm101090p

(34) Wang, C.; Waje, M.; Wang, X.; Tang, J. M.; Haddon, R. C.; Yan, Y. S. Nano Lett. 2004, 4 (2), 345. doi: 10.1021/n1034952p

(35) Erlebacher, J.; Aziz, M. J.; Karma, A.; Dimitrov, N.; Sieradzki, K. Nature 2001, 410 (6827), 450. doi: 10.1038/35068529

(36) Meng, F. H.; Ding, Y. Adv. Mater. 2011, 23 (35), 4098. doi: 10.1002/adma.201101678

(37) Wang, R.; Liu, J.; Liu, P.; Bi, X.; Yan, X.; Wang, W.; Ge, X.; Chen, M.; Ding, Y. Chem. Sci. 2014, 5 (1), 403. doi: 10.1039/c3sc52792a

(38) Wang, R.; Liu, J.; Liu, P.; Bi, X.; Yan, X.; Wang, W.; Meng, Y.; Ge, X.; Chen, M.; Ding, Y. Nano Research 2014, 7 (11), 1569. doi: 10.1007/s12274-014-0517-9

(39) Xiong, W. H.; Zhang, W. C.; Yu, C. P.; Shen, R. Q.; Cheng, J.; Ye, J. H.; Qin, Z. C. Acta Phys. -Chim. Sin. 2016, 32, 2093. [熊文慧，张文超， 俞春培, 沈瑞琪, 程 佳, 叶家海, 秦志春. 物理化学学报, 2016, 32, 2093.] doi: 10.3866/ PKU.WHXB201604082

(40) Nishio, K.; Masuda, H. Angew. Chem. Int. Ed. 2011, 50 (7), 1603. doi: 10.1002/anie. 201005700

(41) Naeth, O.; Stephen, A.; Roesler, J.; Vollertsen, F. J. Mater. Process. Technol. 2009, 209 (10), 4739. doi: 10.1016/j.jmatprotec.2008.11.042

(42) Tappan, B. C.; Steiner, S. A.; Luther, E. P. Angew. Chem. Int. Ed. 2010, 49 (27), 4544. doi: 10.1002/anie.200902994

(43) Guo, X. Z.; Ding, L.; Yu, H.; Shan, J. Q.; Yang, H. Acta Phys. -Chim. $\operatorname{Sin}$ 2016, 32, 1727. [郭兴忠, 丁 力, 于 欢, 单加琪, 杨 辉. 物 
理化学学报, 2016, 32, 1727.] doi: 10.3866/PKU.WHXB201604082

(44) Nie, L. H.; Tan, Q.; Zhu, W.; Wei, Q.; Lin, Z. K. Acta Phys. -Chim. Sin. 2015, 31, 1815. [聂龙辉, 谭 侨, 朱 玮, 魏 琪, 林志奎. 物理化 学学报, 2015, 31, 1815.] doi: 10.3866/PKU.WHXB20150720

(45) Erlebacher, J. J. Electrochem. Soc. 2004, 151 (10), C614. doi: $10.1149 / 1.1784820$

(46) Zhang, Z. H.; Wang, Y.; Qi, Z.; Zhang, W. H.; Qin, J. Y.; Frenzel, J. J. Phys. Chem. C 2009, 113 (29), 12629. doi: 10.1021/jp811445a

(47) Yeh, F. H.; Tai, C. C.; Huang, J. F.; Sun, I. W. J. Phys. Chem. B 2006, 110 (11), 5215. doi: 10.1021/jp0552527

(48) Lei, W.; Briot, N. J.; Swartzentruber, P. D.; Balk, T. J. Metall. Mater. Trans. A 2014, 45 (1), 1. doi: 10.1007/s11661-013-2127-7

(49) Hayes, J. R.; Hodge, A. M.; Biener, J.; Hamza, A. V.; Sieradzki, K. J. Mater. Res. 2006, 21 (10), 2611. doi: 10.1557/jmr.2006.0322

(50) Renner, F. U.; Stierle, A.; Dosch, H.; Kolb, D. M.; Lee, T. L.; Zegenhagen, J. Nature 2006, 439 (7077), 707. doi: $10.1038 /$ nature 04465

(51) Chen, L. Y.; Chen, N.; Hou, Y.; Wang, Z. C.; Lv, S. H.; Fujita, T.; Jiang, J. H.; Hirata, A.; Chen, M. W. ACS Catal. 2013, 3 (6), 1220. doi: $10.1021 / \mathrm{cs} 400135 \mathrm{k}$

(52) Xu, C. X.; Su, J. X.; Xu, X. H.; Liu, P. P.; Zhao, H. J.; Tian, F.; Ding, Y. J. Am. Chem. Soc. 2007, 129 (1), 42. doi: 10.1021/ja0675503

(53) Liu, W.; Herrmann, A. K.; Bigall, N. C.; Rodriguez, P.; Wen, D.; Oezaslan, M.; Schmidt, T. J.; Gaponik, N.; Eychmuller, A. Acc. Chem. Res. 2015, 48 (2), 154. doi: 10.1021/ar500237c

(54) Geng, D. S.; Ding, N.; Hor, T. S. A.; Liu, Z. L.; Sun, X. L.; Zong, Y. J. Mater. Chem. A 2015, 3 (5), 1795. doi: 10.1039/c4ta06008c

(55) Qi, Z.; Weissmüller, J. ACS Nano 2013, 7 (7), 5948. doi: $10.1021 / \mathrm{nn} 4021345$

(56) Gan, L.; Heggen, M.; O'Malley, R.; Theobald, B.; Strasser, P. Nano Lett. 2013, 13 (3), 1131. doi: 10.1021/n1304488q

(57) Cheng, I. C.; Hodge, A. M. J. Porous Mater. 2014, 21 (4), 467. doi: $10.1007 / \mathrm{s} 10934-014-9793-8$

(58) Cahn, J. W. Acta Metall. 1961, 9 (9), 795. doi: 10.1002/9781118788295.ch11

(59) Park, M.; Harrison, C.; Chaikin, P. M.; Register, R. A.; Adamson, D. H. Science 1997, 276 (5317), 1401. doi: 10.1126/science.276.5317.1401

(60) Fukutani, K.; Tanji, K.; Motoi, T.; Den, T. Adv. Mater. 2004, 16 (16), 1456. doi: 10.1002/adma.200400268

(61) Ding, Y.; Chen, M. W. MRS Bull. 2009, 34 (8), 569. doi: $10.1557 / \mathrm{mrs} 2009.156$

(62) Ding, Y.; Chen, M.; Erlebacher, J. J. Am. Chem. Soc. 2004, 126 (22), 6876. doi: 10.1021/ja0320119

(63) Fujita, T.; Tokunaga, T.; Zhang, L.; Li, D.; Chen, L.; Arai, S.; Yamamoto, Y.; Hirata, A.; Tanaka, N.; Ding, Y. Nano Lett. 2014, 14 (3), 1172. doi: $10.1021 / \mathrm{n} 1403895 \mathrm{~s}$
(64) Fujita, T.; Okada, H.; Koyama, K.; Watanabe, K.; Maekawa, S.; Chen, M. W. Phys. Rev. Lett. 2008, 101 (16), 166601.

doi: 10.1103/PhysRevLett.101.166601

(65) Xia, R.; Wang, J. L.; Wang, R. Y.; Li, X. D.; Zhang, X.; Feng, X. Q.; Ding, Y. Nanotechnology 2010, 21 (8), 085703. doi: 10.1088/0957-4484/21/8/085703

(66) Fujita, T.; Qian, L. H.; Inoke, K.; Erlebacher, J.; Chen, M. W. Appl. Phys. Lett. 2008, 92 (25), 251902. doi: 10.1063/1.2948902

(67) Liu, P.; Guan, P.; Hirata, A.; Zhang, L.; Chen, L.; Wen, Y.; Ding, Y.; Fujita, T.; Erlebacher, J.; Chen, M. Adv. Mater. 2016, 28 (9), 1753. doi: 10.1002/adma.201504032

(68) Rösner, H.; Parida, S.; Kramer, D.; Volkert, C. A.; Weissmüller, J. Adv Eng. Mater. 2007, 9 (7), 535. doi: 10.1002/adem.200700063

(69) Pia, G.; Brun, M.; Aymerich, F.; Delogu, F. J. Mater. Sci. 2017, 52 (2), 1106. doi: 10.1007/s10853-016-0407-5

(70) Zhang, X.; Ding, Y. Catal. Sci. Technol. 2013, 3 (11), 2862. doi: $10.1039 / \mathrm{c} 3$ cy00241a

(71) Gu, X. H.; Xu, L. Q.; Tian, F.; Ding, Y. Nano Res. 2009, 2 (5), 386. doi: 10.1007/s12274-009-9038-3

(72) Yan, X. J.; Xiong, H. Y.; Bai, Q. G.; Frenzel, J.; Si, C. H.; Chen, X. T.; Eggeler, G.; Zhang, Z. H. RSC Adv. 2015, 5 (25), 19409. doi: $10.1039 / \mathrm{c} 4 \mathrm{ra} 17014 \mathrm{~h}$

(73) Ding, Y.; Kim, Y. J.; Erlebacher, J. Adv. Mater. 2004, 16 (21), 1897. doi: 10.1002/adma.200400792

(74) Norskov, J. K.; Rossmeisl, J.; Logadottir, A.; Lindqvist, L.; Kitchin, J. R.; Bligaard, T.; Jonsson, H. J. Phys. Chem. B 2004, 108 (46), 17886. doi: $10.1021 /$ jp047349j

(75) Zhang, J. L.; Vukmirovic, M. B.; Sasaki, K.; Nilekar, A. U.; Mavrikakis, M.; Adzic, R. R. J. Am. Chem. Soc. 2005, 127 (36), 12480. doi: $10.1021 / \mathrm{ja} 053695 \mathrm{i}$

(76) Koh, S.; Strasser, P. J. Am. Chem. Soc. 2007, 129 (42), 12624. doi: $10.1021 /$ ja0742784

(77) Srivastava, R.; Mani, P.; Hahn, N.; Strasser, P. Angew. Chem. Int. Ed. 2007, 46 (47), 8988. doi: 10.1002/anie.200703331

(78) Wang, D.; Zhao, P.; Li, Y. Sci. Rep. 2011, 1 (7), 37. doi: $10.1038 /$ srep00037

(79) Oezaslan, M.; Heggen, M.; Strasser, P. J. Am. Chem. Soc. 2012, 134 (1), 514. doi: $10.1021 / \mathrm{ja} 2088162$

(80) Li, X.; Chen, Q.; Mccue, I.; Snyder, J.; Crozier, P.; Erlebacher, J.; Sieradzki, K. Nano Lett. 2014, 14 (5), 2569. doi: 10.1021/nl500377g

(81) Snyder, J.; McCue, I.; Livi, K.; Erlebacher, J. J. Am. Chem. Soc. 2012, 134 (20), 8633. doi: $10.1021 /$ ja3019498

(82) Baldizzone, C.; Gan, L.; Hodnik, N.; Keeley, G. P.; Kostka, A.; Heggen, M.; Strasser, P.; Mayrhofer, K. J. J. ACS Catal. 2015, 5 (9), 5000. doi: 10.1021/acscatal.5b01151

(83) Snyder, J.; Fujita, T.; Chen, M. W.; Erlebacher, J. Nat. Mater. 2010, 
9 (11), 904. doi: 10.1038/nmat2878

(84) Benn, E.; Uvegi, H.; Erlebacher, J. J. Electrochem. Soc. 2015, 162 (10), H759. doi: 10.1149/2.0161510jes

(85) Snyder, J.; Livi, K.; Erlebacher, J. Adv. Funct. Mater. 2013, 23 (44), 5494. doi: 10.1002/adfm.201301144

(86) Wang, R. Y.; Xu, C. X.; Bi, X. X.; Ding, Y. Energy Environ. Sci. 2012, 5 (1), 5281. doi: 10.1039/c1ee02243a

(87) Duan, H. M.; Xu, C. X. Electrochim. Acta 2015, 152, 417. doi: $10.1016 /$ j.electacta.2014.11.160

(88) Duan, H. M.; Hao, Q.; Xu, C. X. J. Power Sources 2015, 280, 483. doi: 10.1016/j.jpowsour.2015.01.136

(89) Xu, C. X.; Zhang, H.; Hao, Q.; Duan, H. M. ChemPlusChem 2014, 79 (1), 107. doi: 10.1002/cplu.201300311

(90) Han, B. H.; Xu, C. X. Int. J. Hydrogen Energy 2014, 39 (32), 18247. doi: 10.1016/j.ijhydene.2014.09.006

(91) Chen, X. T.; Jiang, Y. Y.; Sun, J. Z.; Jin, C. H.; Zhang, Z. H. J. Power Sources 2014, 267 (4), 212. doi: 10.1016/j.jpowsour.2014.05.089

(92) Zhang, Z. H.; Wang, Y.; Wang, X. G. Nanoscale 2011, 3 (4), 1663. doi: $10.1039 / \mathrm{c} 0 \mathrm{nr} 00830 \mathrm{c}$

(93) Zhang, Z. H.; Zhang, C.; Sun, J. Z.; Kou, T. Y.; Bai, Q. G.; Wang, Y.; Ding, Y. J. Mater. Chem. A 2013, 1 (11), 3620. doi: $10.1039 / \mathrm{c} 3 \mathrm{ta} 01464 \mathrm{a}$

(94) Lang, X. Y.; Han, G. F.; Xiao, B. B.; Gu, L.; Yang, Z. Z.; Wen, Z.; Zhu, Y. F.; Zhao, M.; Li, J. C.; Jiang, Q. Adv. Funct. Mater. 2015, 25 (2), 230. doi: 10.1002/adfm.201401868

(95) Zeis, R.; Lei, T.; Sieradzki, K.; Snyder, J.; Erlebacher, J. J. Catal. 2008, 253 (1), 132. doi: 10.1016/j.jcat.2007.10.017
(96) Shao, M. J. Power Sources 2011, 196 (5), 2433.

doi: 10.1016/j.jpowsour.2010.10.093

(97) Xu, C. X.; Zhang, Y.; Wang, L. Q.; Xu, L. Q.; Bian, X. F.; Ma, H. Y.; Ding, Y. Chem. Mater. 2009, 21 (14), 3110. doi: $10.1021 / \mathrm{cm} 900244 \mathrm{~g}$

(98) Xu, C. X.; Wang, L. Q.; Wang, R. Y.; Wang, K.; Zhang, Y.; Tian, F.; Ding, Y. Adv. Mater. 2009, 21 (21), 2165. doi: 10.1002/adma.200702700

(99) Zhang, H.; Hao, Q.; Geng, H. R.; Xu, C. X. Int. J. Hydrogen Energy 2013, 38 (24), 10029. doi: 10.1016/j.ijhydene.2013.06.010

(100) Yang, R. Z.; Bian, W. Y.; Strasser, P.; Toney, M. F. J. Power Sources 2013, 222 (2), 169. doi: 10.1016/j.jpowsour.2012.08.064

(101) Xu, C.; Liu, Y.; Zhang, H.; Geng, H. Chem. - Asian J. 2013, 8 (11), 2721. doi: 10.1002/asia.201300607

(102) Xu, C. X.; Liu, Y. Q.; Hao, Q.; Duan, H. M. J. Mater. Chem. A 2013, 1 (43), 13542. doi: 10.1039/c3ta12765f

(103) Liu, Y.; Xu, C. ChemSusChem 2013, 6 (1), 78. doi: $10.1002 /$ cssc. 201200752

(104) Zhou, Y.; Lu, Q.; Zhuang, Z. B.; Hutchings, G. S.; Kattel, S.; Yan, Y. S.; Chen, J. G.; Xiao, J. Q.; Jiao, F. Adv. Eng. Mater. 2015, 5 (13), 1500149. doi: 10.1002/aenm.201500149

(105) Xu, C. X.; Li, Y. Y.; Tian, F.; Ding, Y. ChemPhysChem 2010, 11 (15), 3320. doi: 10.1002/cphc.201000313

(106) Gu, X.; Cong, X.; Ding, Y. ChemPhysChem 2010, 11 (4), 841. doi: $10.1002 /$ cphc. 200900927

(107) Chen, B.; Meng, G. W.; Huang, Q.; Huang, Z. L.; Xu, Q. L.; Zhu, C. H.; Qian, Y. W.; Ding, Y. ACS Appl Mater Inter 2014, 6 (18), 15667. doi: 10.1021/am505474n 